\title{
Tungsten Doped Monodispersed Titania Particles
}

\author{
Nataliya Murafa*, Václav Šteng1*, Vendula Houšková* \\ *Institute of Inorganic Chemistry of the ASCR, v. v. i., 25068 Řež, Czech Republic
}

Titanium $\left(\mathrm{TiO}_{2}\right)$ dioxide is a semiconductor with a well-known photocatalytic activity [1]. Increasing concerns over the natural environmental contamination induce strong scientific interest which has been focused on environmental regeneration, including self-cleaning materials. $\mathrm{TiO}_{2}$ widely used in fields such as environmental purification, decomposition of carbonic acid gases, and solar cells $[2,3]$. For example, $\mathrm{TiO}_{2}$-based photo-catalysts have been used to break down organic compounds in wastewater [4]. Indeed, many organic pollutants can be degraded and ultimately mineralized using $\mathrm{TiO}_{2}$ photo-catalysts in the presence of UV radiation [5]. It is well known that properties such inorganic materials are directly dependent on their structure and morphology. Chemical compounds of the same composition but different morphology can show out profoundly different properties. This is the reason why scientists carefully investigate new structural and morphological properties of photocatalytic materials.

In this work, we assess properties of tungstem doped monodispersed titania particles. In a typical experiment, titanyl oxo-sulphate was dissolved in $100 \mathrm{ml}$ of distilled water $(1.6 \mathrm{M})$ and hydrolyzed by slow addition of ammonium hydroxide solution (10\%) under constant stirring at temperature of $0^{\circ} \mathrm{C}$ in ice bath, until the reaction mixture reaches $\mathrm{pH}$ 8.0. The obtained white precipitate was separated by filtration and was washed free of sulphate ions (confirmed by the $\mathrm{BaCl}_{2}$ test) with distilled water. Obtained wet precipitate was mixed with $100 \mathrm{ml}$ of $30 \% \mathrm{H}_{2} \mathrm{O}_{2}$ solution and yellow gelatinous mass was obtained. The yellow see-through gelatin product obtained by foregoing reaction was mixed with defined amount of sodium tungstate dehydrate $\mathrm{Na}_{2} \mathrm{WO}_{4} \cdot 2 \mathrm{H}_{2} \mathrm{O}$ diluted with $10 \mathrm{ml} \mathrm{H} \mathrm{O}_{2}$ and subsequently heated in heating mantle in round-bottom flask with a reflux cooler. During the heating process white precipitate originated. Annealing had been continued till the precipitate changed its color to white or slightly yellow ( 36 hours). The obtained precipitate was dried in the oven at $105^{\circ} \mathrm{C}$.

The prepared samples were characterized by several instrumental techniques XRD (X-ray Powder Diffraction), EDX (Energy Dispersive X-ray), BET (Surface Area), BJH (Porosity), TEM (Transmission Electron Microscopy), and HRTEM (High Resolution Transmission Electron Microscopy).

HRTEM images of $\mathrm{W}^{6+}$ doped anatase particles are shown in Fig 1. The aspect ratio of anatase particle decreased gradually with the addition of tungsten, and changes the morphology of particles from spindle-like shapes to the shape of rectangular or square cross-section. The HRTEM image confirms that the particles are of anatase structure. The fine fringe spacing $d$ along the [101] direction of the anatase crystal linearly increased with the amount of doping agent. These images clearly show that this is a very good crystalline material, in contrast to initial material Fig. 1(a), which contains no amorphous domains. The absence of these amorphous domains is an essential prerequisite for good photocatalytic properties. 


\section{References:}

[1] M.V. Shankar et al., Journal of Colloid and Interface Science 331 (2009) 132-137

[2] S.-A. Lee, K.-H. Choo, C.H. Lee et al., Ind. Eng. Chem. Res. 40 (2001) 1712

[3] W. Choi, Catal. Surv. Asia 10 (2006) 16

[4] M.R. Hoffmann, S.T. Martin, W. Choi, D.W. Bahnemann, Chem. Rev. 95 (1995) 69

[5] J.M. Macak, M. Zlamal, J. Krysa, P. Schmuki, Small 3 (2007) 300

[6] This work was supported by the Academy of Sciences of the Czech Republic (AV OZ 40320502)
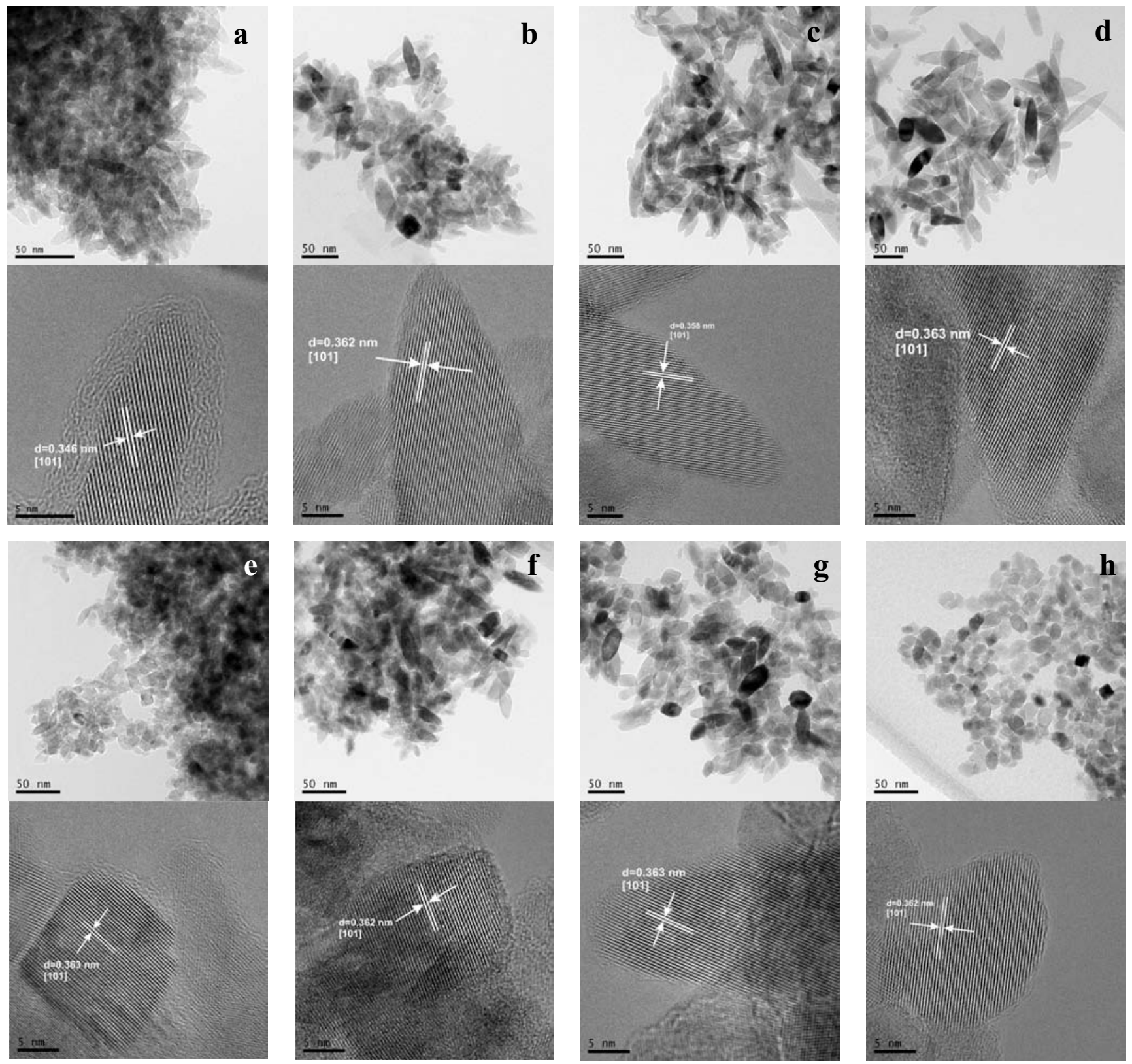

Fig. 1. TEM and HRTEM micrographs of tungsten doped nanodispersed particles of titania (a) - initial material, (b) - 0.05g, (c) - 0.1g, (d) - 0.15g, (e) - 0.25g, (f) - 0.5g, (g) - 1g, (h) - 2g 